\title{
Características tecnológicas de farinhas vegetais comerciais
}

\author{
Gabriela Silva Santana ${ }^{1}$, Josemar Gonçalves de Oliveira Filho ${ }^{2}$, Mariana Buranelo Egea ${ }^{2}$ \\ ${ }^{1}$ Instituto Federal de Educação, Ciência e Tecnologia Goiano, Campus Morrinhos, Morrinhos, Goiás, Brasil. E-mail: \\ gabrielasantanang@gmail.com \\ ${ }^{2}$ Instituto Federal de Educação, Ciência e Tecnologia Goiano, Campus Rio Verde, Rio Verde, Goiás, Brasil. E-mail: \\ josemar.gooliver@gmail.com, mariana.egea@ifgoiano.edu.br
}

Recebido:11/03/2017; Aceito: 01/06/2017

\section{RESUMO}

As farinhas são muito utilizadas no processamento de diversos produtos de panificação e o seu desempenho tecnológico depende de características funcionais previamente descritas. O objetivo deste trabalho foi avaliar as propriedades funcionais tecnológicas de farinhas comerciais de origem vegetal. Foram realizadas análises de índice de absorção de água, capacidade de absorção de óleo, solubilidade em água, capacidade de formação de espuma, estabilidade da espuma, capacidade emulsificante, estabilidade da emulsão e capacidade de formação de gel. A farinha da casca de maracujá apresentou o maior índice de absorção de água $(4,85 \%)$. Todas as farinhas apresentaram valores satisfatórios para capacidade de absorção de óleo. Os maiores valores de solubilidade em água foram apresentados pelas farinhas de linhaça dourada, feijão branco, linhaça marrom, uva e maracujá. Apenas as farinhas comerciais de trigo integral, feijão branco, banana, trigo branca e soja apresentaram capacidade espumante e estabilidade da espuma durante 120 minutos. Exceto pelas farinhas de uva e trigo branca, as farinhas comerciais avaliadas demonstraram atividade emulsificante interessante para a indústria de alimentos. As farinhas de aveia A e B e trigo branca, apresentaram formação de gel já na menor concentração avaliada. As farinhas vegetais comerciais estudadas apresentaram características que permitem seu uso como ingrediente para diversas aplicações de interesse para a indústria de alimentos.

Palavras-chave: gelatinização, absorção de água, emulsão, aplicação tecnológica.

\section{Characteristics technological of commercial vegetable flours}

\begin{abstract}
Flours are widely used in the processing of various bakery products and their technological performance depends on the functional characteristics previously described. The objective of this study was to evaluate the technological functional properties of commercial flours of vegetable origin. Analyzes were performed, water absorption index, oil absorption capacity, water solubility, foamability, foam stability, emulsifying capacity, emulsion stability and gelatinization. The flour of the passion fruit peel had the highest water absorption index (4.85\%). All flours presented satisfactory values for oil absorption capacity. The highest values of water solubility were presented by flours of gold flax, white beans, brown flax, grape and passion fruit. Only the commercial flours of whole wheat, white beans, bananas, normal wheat, and soybeans showed foam capacity and the stability of the foam for 120 minutes. Except for normal grapes and wheat flours, the commercial flours evaluated showed interesting emulsifying activity for the food industry. Oat flours A and B and normal wheat showed gel formation at the lowest evaluated concentration. The commercial vegetable flours studied presented characteristics that allow their use as an ingredient for various applications of interest to the food industry.
\end{abstract}

Key words: gelatinization, water absorption, emulsion, technological application. 


\section{Introdução}

Farinhas são produtos obtidos de partes comestíveis de uma ou mais espécies de cereais, leguminosas, frutos, sementes, tubérculos e rizomas por moagem e/ou outros processos tecnológicos considerados seguros para produção de alimentos (BRASIL, 2005a).

$\mathrm{O}$ aumento na demanda por alimentos no mundo tem motivado a procura por fontes alternativas para a alimentação bem como por novos processos tecnológicos, visando à redução dos custos dos produtos e de impacto positivo no atendimento das demandas nutricionais (CASTILHO et al., 2010).

Neste contexto, a utilização de farinhas vegetais como ingredientes desempenha um papel importante nas indústrias de alimentos devido ao seu baixo custo de produção comparado com os concentrados proteicos. Estas farinhas podem ser utilizadas como alternativa para substituição da farinha de trigo, para compor farinhas mistas na elaboração de produtos de panificação (biscoitos e pães) e massas alimentícias (SILVEIRA et al., 2016).

A aplicação de farinhas vegetais depende do seu desempenho como ingredientes funcionais e do seu comportamento tecnológico em determinados sistemas alimentares durante o processamento dos alimentos ou para a qualidade do produto final e por isso, é de extrema importância caracterizá-lo antes mesmo da sua aplicação (GUIMARÃES et al., 2012; TAVARES et al., 2012).

As propriedades funcionais tecnológicas são propriedades de um ingrediente, não diretamente relacionadas aos seus fatores nutricionais, mas são propriedades que influenciam na aparência física do alimento e no seu comportamento influenciando o seu consumo. Normalmente, estas propriedades estão relacionadas aos componentes químicos, como as proteínas, por exemplo, que têm a capacidade de exercer absorção de água, formação e estabilidade de emulsão, formação de gel e espuma, dentre outras (MIZUBUTI et al., 2000).

As propriedades funcionais tecnológicas têm recebido atenção em novos ingredientes alimentares pois afetam as características nutritivas e sensoriais, a aparência física do produto, a preparação de alimentos elaborados com estas matérias primas e o processamento ou estocagem de maneira característica que resulta das propriedades físico-químicas da matériaprima proteica (SEIBEL; BELÉIA, 2009; PORTE et al., 2011).

O objetivo do trabalho foi a avaliação das propriedades funcionais tecnológicas de farinhas comerciais de origem vegetal: aveia, banana, feijão branco, linhaça dourada e marrom, maracujá, soja, trigo integral e normal, e uva.

\section{Material e Métodos}

As farinhas de aveia (duas marcas foram avaliadas), banana, feijão branco, linhaça dourada e marrom, maracujá, soja, trigo branca e trigo integral e uva foram obtidas no comércio local de Morrinhos (Goiás, Brasil).

O índice de absorção de água (IAA) foi determinado de acordo com metodologia de Okezie e Bello (1988). Uma suspensão foi preparada pela mistura de $0,5 \mathrm{~g}$ de farinha e $25 \mathrm{~mL}$ de água, agitada e em seguida centrifugada a $5300 \mathrm{rpm}$ por 20 minutos. O líquido sobrenadante foi escorrido e o material remanescente (farinha úmida) foi pesado. O líquido sobrenadante foi utilizado para a determinação da solubilidade em água (SA) das farinhas comerciais, evapou-se a água em placa de Petri previamente tarada em estufa à $105^{\circ} \mathrm{C}$ até peso constante. Para a determinação da capacidade de absorção de óleo (CAO) a mesma metodologia foi utilizada empregando-se óleo de soja no lugar da água. O Índice de absorção de água (IAA), Capacidade de absorção de óleo (CAO) e Solubilidade em água (SA) foram calculados conforme as Equações 1, 2 e 3.

$$
\begin{aligned}
& I A A=\frac{\text { água absorvida pela amostra }(g)}{\text { peso da amostra }(g)} \\
& C A O=\frac{\text { óleo absorvido pela amostra }(g)}{\text { amostra }(g)} \\
& S A=\frac{\text { resíduo de evaporação }(g)}{\text { peso da amostra }(g)} \times 100
\end{aligned}
$$

A atividade emulsificante das farinhas comerciais foi determinada utilizando a metodologia descrita por Yasumatsu et al. (1972), procedeu-se à homogeneização em agitador mecânico eletrônico macro-Q250 (DIADEMA, São Paulo); 1,0 g de amostra em 10 mL de água e $10 \mathrm{ml}$ de óleo de soja, dividiu-se em tubos graduados de $15 \mathrm{ml}$ e centrifugado a $3000 \mathrm{rpm}$ por 5 minutos. A atividade emulsificante foi calculada de acordo com a Equação 4. Para determinar a estabilidade da emulsão, os tubos foram aquecidos em banho-maria à $80{ }^{\circ} \mathrm{C}$ por 30 minutos; em seguida resfriados por 20 minutos em água corrente e centrifugados a $3000 \mathrm{rpm}$ por 5 minutos. A estabilidade da emulsão foi calculada pela Equação 5 .

A capacidade espumante foi determinada pela metodologia de Coffmann e Garcia (1977), por agitação de $1,0 \mathrm{~g}$ de farinha com $50 \mathrm{~mL}$ de água por 5 minutos em agitador; o volume foi transferido para uma proveta de $100 \mathrm{~mL}$ e calculado seu aumento percentual com base nos volumes inicial de acordo com a Equação 6. A estabilidade da espuma foi medida ao deixar a proveta em temperatura ambiente $\left(25^{\circ} \mathrm{C} \pm 0,02\right)$ e observada nos intervalos de 30, 60, 90 e 120 minutos. 


$$
\text { Atividade emulsificante }=\frac{\text { camada emulsificada }(\mathrm{ml})}{\text { volume total no tubo }(\mathrm{ml})} \times 100
$$

$$
\begin{gathered}
\text { Estabilidade da emulsão }=\frac{\text { camada emulsificada remanescente }(\mathrm{ml})}{\text { camada emulsificada no tubo }(\mathrm{ml})} \times 100 \\
\% \text { Aumento de volume }=\frac{\text { volume final }- \text { volume inicial }}{\text { volume inicial }} \times 100
\end{gathered}
$$

A capacidade de formação de gel da farinha foi determinada de acordo com Coffmann e Garcia (1977). Dispersões de concentrações das amostras (2\%, 4\%, $6 \%, 8 \%, 10 \%, 12 \%, 14 \%, 16 \%, 18 \%$ e $20 \%$ ) foram realizadas em $20 \mathrm{~mL}$ de água e submetidas ao aquecimento à $90^{\circ} \mathrm{C}$ por 30 minutos. Em seguida, foram resfriadas à temperatura ambiente e refrigeradas à $4{ }^{\circ} \mathrm{C}$ por 2 horas. Em seguida os tubos foram invertidos e analisados quanto à formação de gel.

Para análise estatística dos dados foi utilizado o delineamento inteiramente casualizado e resultados experimentais foram comparados por ANOVA e teste de Tukey para determinação da diferença estatística entre as médias $(\mathrm{p}<0,05)$, utilizando-se o programa STATISTICA 8.0.

\section{Resultados e Discussão}

A Figura 1 apresenta o índice de absorção de água (IAA), a capacidade de absorção de óleo (CAO) e a solubilidade em água (SA) das farinhas de origem vegetal.

A farinha de maracujá apresentou maior índice de absorção de água com diferença significativa $(\mathrm{p}<0,05)$ para todas as outras farinhas de origem vegetal analisadas. Ainda assim, o IAA da farinha de maracujá $(4,85 \%)$ foi menor do que o valor que havia sido relatado por Souza et al. (2008) para farinha da casca de maracujá $(6,02 \%)$. A absorção de água de farinhas de origem vegetal é atribuída principalmente ao elevado teor de fibras normalmente encontrado nestas farinhas (PORTE et al., 2011); fator que pode ser o responsável pelo maior valor encontrado no IAA da farinha da casca de maracujá. O teor de fibras na farinha da casca do maracujá é elevado $60 \mathrm{~g} / 100 \mathrm{~g}$ (dados não apresentados fornecidos pela empresa no rótulo do produto), e este valor é superior ao encontrado nas demais farinhas comerciais avaliadas neste trabalho.

O IAA das farinhas de aveia A $(0,85 \%)$ e B $(1,20 \%)$, e trigo branco $(1,15 \%)$ (sem diferença estatística entre elas) foi quase 4 vezes menor que o IAA da farinha de maracujá $(4,85 \%)$. Na farinha de trigo o IAA baixo provavelmente ocorreu pelo alto conteúdo de amido e por ele apresentar baixa solubilidade em água fria, somente 30\% (FENNEMA, 2010).

Khattab e Arntfield (2009) encontraram resultado de IAA para farinha soja $(3,28 \mathrm{~g} / \mathrm{g})$ superior ao encontrado neste estudo (2,48 g/g). Esses mesmos autores descreveram valor de IAA para semente de canola de $3,90 \mathrm{~g} / \mathrm{g}$, valor superior aos dados apresentados na Figura 1, exceto para a farinha de maracujá que apresentou valor superior $(4,85 \mathrm{~g} / \mathrm{g})$. Valor de IAA similar ao encontrado para as farinhas de feijão branco, soja, uva e linhaça marrom foi relatado por Zambrano et al. (2001) para farinha de milho $(2,32 \mathrm{~g} / \mathrm{g})$.

O índice de absorção em água (IAA) de uma farinha é considerado viável para avaliação do acréscimo deste componente em produtos cárneos, pães e bolos, permitindo a adição de água a fim de facilitar o manuseio da massa e evitar seu ressecamento, durante o armazenamento (PORTE et al., 2011; CLERICI; ELDASH, 2008). Sendo assim, quanto maior a porcentagem de farinha de maracujá, utilizada para a elaboração destes produtos, maior será a absorção de água e, consequentemente, mais líquido poderá ser utilizado no processo, diminuindo, possivelmente, os custos de produção.

Quanto ao IAA, ordenando em ordem decrescente temos: maracujá > soja > uva > linhaça dourada > linhaça marrom $>$ feijão branco $>$ banana $>$ trigo integral $>$ aveia $\mathrm{B}>$ trigo branca $>$ aveia $\mathrm{A}$.

A Capacidade de Absorção de Óleo (CAO) é conferida, principalmente, à ligação de partes proteicas da amostra às moléculas do óleo. Altos índices de absorção em óleo determinam se a farinha poderá ser utilizada em produtos cárneos ou em produtos emulsionados como massas de bolos, maionese ou molhos para saladas, sopas, queijos processados e extensores de carne (SILVA-SÁNCHEZ et. al., 2004; PORTE et al., 2011).

De acordo com Rodriguez-Ambriz et al. (2005) esta característica melhora a palatabilidade do alimento por conferir propriedades adequadas de consistência, viscosidade e adesão, melhorando a qualidade da textura e facilitando seu uso como ingredientes análogos ou substitutos em formulações alimentares. 


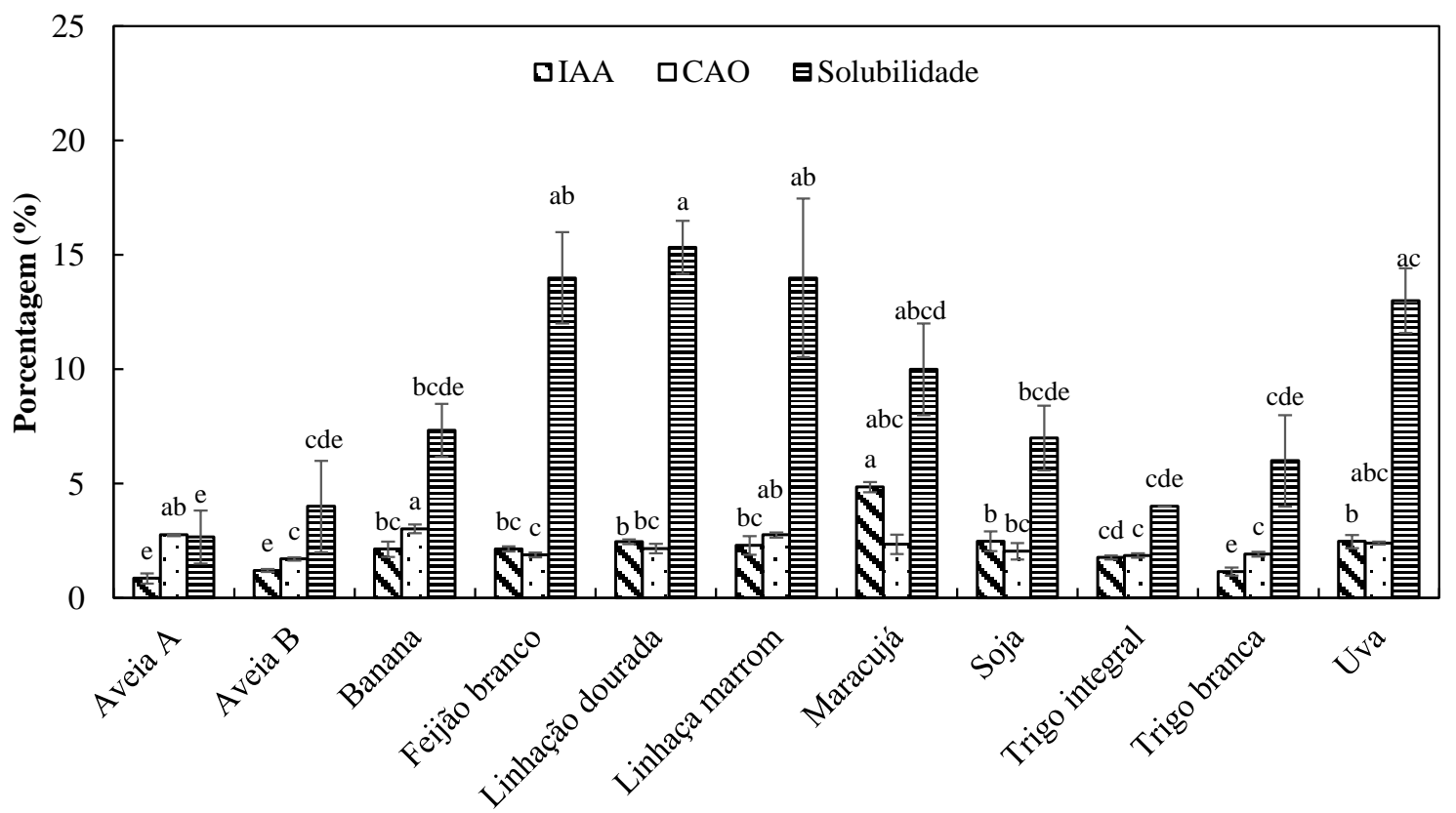

Figura 1. Índice de absorção de água (IAA), Capacidade de absorção de óleo (CAO) e Solubilidade em água de farinhas comerciais. Letras minúsculas diferentes indicam diferença estatística $(\mathrm{p}<0,05)$ entre as farinhas na análise realizada.

As farinhas de banana, aveia A, linhaça marrom, uva e maracujá apresentaram os maiores valores de CAO (sem diferença estatística entre elas), 3,02; 2,75; 2,75; 2,39 e 2,35, respectivamente. A CAO dessas farinhas pode estar relacionada com a presença de grupos hidrofóbicos expostos nas proteínas dessas farinhas. Segundo Dench et al. (1981), a absorção de gordura varia em função do número de grupos hidrofóbicos expostos da proteína e da interação destes com as cadeias hidrofóbicas da gordura.

Entre as marcas de aveia, houve diferença significativa, sendo a CAO da aveia A $(2,75)$ maior que a aveia B (1,70). Essa diferença pode estar relacionada com uma maior presença de grupos hidrofóbicos expostos nas proteínas presente na farinha de aveia $\mathrm{A}$ $(7,3 \mathrm{~g})$, que apresenta teor de proteínas superior ao encontrado na farinha de aveia B. (4,3 g) (dados não apresentados fornecidos pela empresa no rótulo do produto).

Castilho et al. (2010), encontraram CAO para a farinha de tremoço doce $(1,2-1,3)$ e farinha de feijão gandu (2,0-2,1 \%), sugerindo que essas farinhas apresentam valores satisfatórios para desempenharem funcionalidade em alimentos industrializados. Desta forma, como todas as farinhas vegetais analisadas neste estudo apresentaram valores de CAO similares ou superiores ao encontrados por esses autores, sugere-se que todas elas podem determinar funcionalidade em alimentos industrializados.

Resultados inferiores aos relatados neste estudo foram descritos por Fiorda et al. (2013), em pesquisa com aproveitamento do bagaço da mandioca, cujo CAO foi de $0,59 \mathrm{~g}$ gel/g de matéria seca na farinha do bagaço da mandioca.

Quanto a CAO, ordenando em ordem decrescente segue: banana > aveia $\mathrm{A}=$ linhaça marrom > uva > maracujá $>$ linhaça dourada $>$ soja $>$ trigo branca $>$ feijão branco $>$ trigo integral $>$ aveia B.

Os maiores valores de SA encontrados neste trabalho foram demonstrados pelas farinhas de linhaça dourada $(15,33)$, feijão branco $(14,00)$, linhaça marrom $(14,00)$, uva $(13,00)$ e maracujá $(10,00)$, sem diferença estatística entre elas. Os menores valores foram das farinhas de soja, trigo branca, trigo integral, aveia A e B.

Tavares et al., (2012), encontrou valores de SA de $1,2 \%$ para farinha de arroz cru, valor inferior aos encontrados neste estudo. A SA da farinha de feijão branco $(14 \%)$ foi próximo ao relatado por Gomes et al. (2012); 18-20\%. Farinhas com elevados valores de SA podem ser empregadas em alimentos que requerem baixas temperaturas para serem preparados (instantâneos) ou como ingredientes para formulação de sopas, sobremesas e molhos, que necessitam de ingredientes com maior solubilidade em água (LEONEL; FREITAS; MISCHAN, 2009).

Quanto ao valor de SA, ordenando em ordem decrescente obseva-se: linhaça dourada > feijão branco $=$ linhaça marrom $>$ uva $>$ maracujá $>$ banana $>$ soja $>$ trigo branca $>$ trigo integral $=$ aveia $\mathrm{B}>$ aveia $\mathrm{A}$.

As propriedades IAA, CAO e SA dependem da quantidade de moléculas solúveis e da intensidade e do tipo de reações que ocorrem durante os tratamentos de preparo das farinhas. Além da gelatinização do amido, que resulta na liberação da amilose e amilopectina de 
seus grânulos, poderá ocorrer também a dextrinização dos componentes do amido e outras reações que conduzem à formação de compostos de baixo peso molecular (SEBIO; CHANG, 2000).

A Figura 2 apresenta a capacidade espumante e a estabilidade da espuma de farinhas comerciais de trigo integral, feijão branco, banana, trigo branca, e soja durante 120 minutos. Não foi observada formação e capacidade espumante nas farinhas de aveia A e B, linhaça dourada e marrom e uva.

A farinha de soja manteve a espuma somente até 60 minutos de avaliação e a partir deste tempo se manteve estável. As farinhas de trigo branca e integral e feijão branco mostraram redução significativa na capacidade espumante somente durante os primeiros 30 minutos de avaliação e a partir deste tempo se mantiveram estáveis.

A não formação e capacidade espumante observada nas farinhas de aveia A e B, linhaça dourada e marrom e uva sugerem, segundo Porte et al. (2011), inadequação no uso destas farinhas como ingredientes em sistemas alimentares que requeiram esta propriedade como sorvetes, mousses, merengues e outros.

Mizubuti et al. (2000) descreveram que a farinha do feijão guandu apresentou capacidade espumante de $36 \%$, valor similar ao encontrado para feijão branco $(35,75 \%)$ neste trabalho. No entanto, a espuma formada pela farinha de feijão guandu diminuiu dentro de 30 minutos com uma perda de $54,72 \%$ de espuma, enquanto a do feijão branco diminuiu em 30 minutos e se manteve estável apresentando uma perda de $12,17 \%$ de espuma.
Segundo Wang et al. (2000), a atividade espumante está muito relacionada com a concentração de proteínas, sendo necessárias proteínas de cadeias flexíveis, pobres em estruturas secundárias e terciárias que se adaptem rapidamente na interfase ar-líquido. Além disso, é preciso que estas proteínas tenham a possibilidade de formar ligações hidrofóbicas na sua superfície. A estabilidade de espuma se relaciona com a qualidade da proteína, sendo necessário que se formem películas coesivas, elásticas, contínuas e impermeáveis ao ar.

Exceto pelas farinhas de uva e trigo branca, as farinhas comerciais avaliadas demonstraram atividade emulsificante alta e tornam-se interessantes para a indústria de alimentos. Maiores valores foram encontrados para as farinhas de linhaça dourada $(55,55 \%)$, soja e linhaça marrom $(53,33 \%)$, feijão branco $(52,22 \%)$, banana $(50,00 \%)$, quinoa $(45,55 \%)$ e trigo integral $(40,00 \%)$, sem diferença significativa entre elas. Alta estabilidade da emulsão após a aplicação de temperatura $\left(90^{\circ} \mathrm{C}\right)$ foi encontrada somente para as farinhas linhaça dourada $(90,19 \%)$ e marrom $(93,75 \%)$, soja $(93,75 \%)$ e de feijão branco $(89,30 \%)$. A atividade e estabilidade da emulsão destas farinhas foi maior do que para farinha de sementes de abóbora $(48,06 \%$ para ambas análises) e farinha de sementes de mamão (48,14\% para ambas análises) (PORTE et al., 2011).

A Tabela 1 apresenta a capacidade e atividade emulsificante das farinhas de origem vegetal. As propriedades emulsionantes normalmente são influenciadas pela qualidade e quantidade de proteína solúvel das farinhas (SIDDIQ et al., 2010).

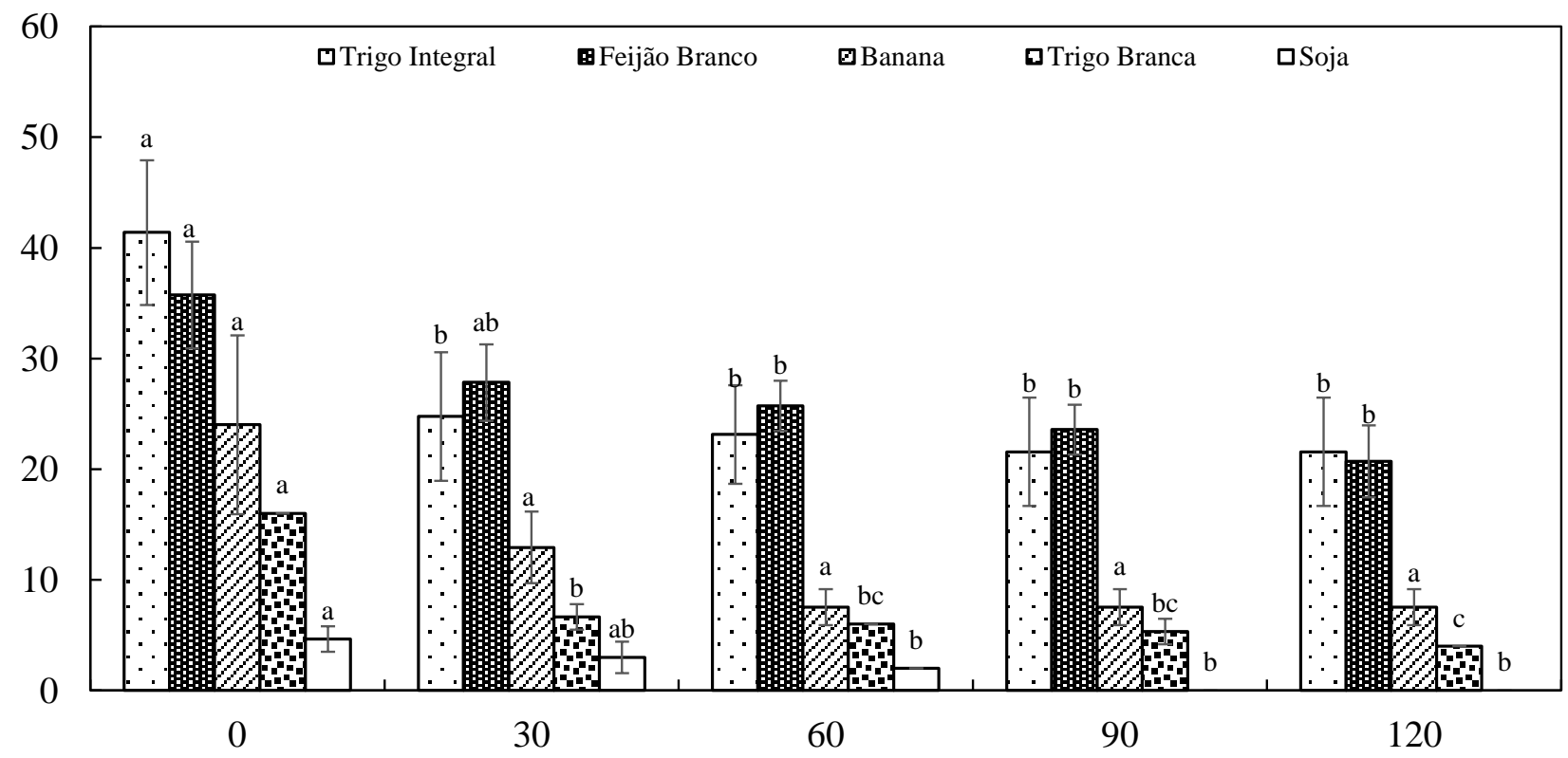

Figura 2 - Capacidade espumante e estabilidade da espuma de farinhas comerciais de trigo integral, feijão branco, banana, trigo branca e soja. Letras minúsculas diferentes indicam diferença estatística $(\mathrm{p}<0,05)$ na estabilidade da espuma durante o tempo avaliado. 
Tabela 1. Atividade emulsificante e estabilidade da emulsão de farinhas comerciais de origem vegetal

\begin{tabular}{lcc}
\hline Farinhas & $\begin{array}{c}\text { Atividade } \\
\text { emulsificante (\%) }\end{array}$ & $\begin{array}{c}\text { Estabilidade da } \\
\text { emulsão (\%) }\end{array}$ \\
\hline Aveia A & $37,78 \pm 8,39^{\mathrm{bc}}$ & $9,11 \pm 1,98^{\mathrm{f}}$ \\
Aveia B & $37,78 \pm 1,92^{\mathrm{bc}}$ & $17,68 \pm 0,87^{\mathrm{f}}$ \\
Banana & $50,00 \pm 3,33^{\mathrm{abc}}$ & $40,12 \pm 2,68^{\mathrm{d}}$ \\
Feijão branco & $52,22 \pm 1,92^{\mathrm{ab}}$ & $89,30 \pm 3,87^{\mathrm{a}}$ \\
Linhaça Dourada & $55,56 \pm 8,39^{\mathrm{a}}$ & $90,19 \pm 2,39^{\mathrm{a}}$ \\
Linhaça Marrom & $53,33 \pm 0,00^{\mathrm{ab}}$ & $93,75 \pm 0,00^{\mathrm{a}}$ \\
Maracujá & $35,56 \pm 13,47^{\mathrm{c}}$ & $31,62 \pm 1,48^{\mathrm{de}}$ \\
Quinoa & $45,56 \pm 1,92^{\mathrm{abc}}$ & $29,30 \pm 7,25^{\mathrm{e}}$ \\
Soja & $53,33 \pm 0,00^{\mathrm{ab}}$ & $93,75 \pm 0,00^{\mathrm{a}}$ \\
Trigo Integral & $40,00 \pm 5,77^{\mathrm{abc}}$ & $33,08 \pm 4,68^{\mathrm{de}}$ \\
Trigo Branca & $13,33 \pm 0,00^{\mathrm{d}}$ & $75,00 \pm 0,00^{\mathrm{b}}$ \\
Uva & $6,67 \pm 0,00^{\mathrm{d}}$ & $50,00 \pm 0,00^{\mathrm{c}}$
\end{tabular}

Letras minúsculas diferentes na mesma coluna indicam diferença significativa $(\mathrm{p}<0,05)$ entre as farinhas na análise realizada.

No desenvolvimento de produtos com alegação de propriedades funcionais de diversas fontes, a aplicação de farinhas em produtos cárneos é muito comum e, neste caso, deseja-se que esta farinha contribua para a formação da emulsão do produto final (CASTILHO et al., 2010). Farinhas com baixa atividade emulsificante como as farinhas de trigo branca e de uva não são de interesse comercial para esta aplicação. Também, farinhas com baixa estabilidade da emulsão previamente formada são inapropriadas em virtude dos tratamentos térmicos realizados com estes produtos. Neste caso, poderiam ser utilizadas as farinhas de linhaça dourada e marrom, soja e feijão branco.

A Tabela 2 apresenta a capacidade de formação de gel das farinhas de origem vegetal na concentração entre 2 - $20 \%$; é utilizada uma medida da quantidade mínima de farinhas para formar um gel num determinado volume de água (BATISTA et al., 2010). O fenômeno de gelificação resulta na formação de uma rede tridimensional de carboidratos modificados ou não por processos térmicos, juntamente com moléculas de proteína e lipídios parcialmente desnaturadas (ADEBOWALE; LAWAL, 2003).

A farinha de soja não apresentou capacidade de formação de gel no teste realizado. Esta farinha pode ser pouco útil para fornecer corpo na fabricação de mingaus, cremes e molhos que dependem da formação de gel da farinha para o aprisionamento da água.

Neste trabalho, houve formação de gel frágil na presença de $4 \%$ de farinha de feijão branco e gel resistente a partir da concentração de 14\%. Este comportamento foi diferente do que havia sido relatado para farinha feijão caupi. No entanto, quanto à capacidade espumante o feijão caupi apresentou maior valor $(51,16 \%)$, enquanto neste trabalho, para o feijão branco, o valor foi de 35,75\% (BATISTA et al., 2010).

As farinhas de aveia A e B e trigo branca, apresentaram formação de gel já na menor concentração avaliada (2\%). Enquanto a aveia B e a farinha de trigo branca formaram gel resistente a partir de $12 \%$, a aveia A apresentou gel resistente a partir de 6\%. Quando comparadas as duas marcas de aveia, a formação de gel resistente na marca $\mathrm{A}$ foi na metade da concentração da formação de gel resistente para a marca B. Para a indústria de alimentos esta comparação é muito importante, pois envolve a quantidade de ingredientes que será utilizado na fabricação de produtos que dependem da formação de gel.

Enquanto isso, a farinha de trigo integral apresentou gel frágil em todas as concentrações analisadas. $\mathrm{O}$ gel frágil encontrado na farinha de trigo integral pode ser o responsável pela dificuldade de aplicação desta farinha em produtos de panificação. Segundo Oro et al. (2013), a viscosidade máxima é um parâmetro relacionado à capacidade do amido em absorver água, e, consequentemente ao grau de intumescimento dos grânulos de amido durante o aquecimento. Assim, quando existem grandes quantidades de grânulos com elevada capacidade de intumescimento, ocorrem elevados picos de viscosidade.

Tabela 2 - Capacidade de formação de gel das farinhas de origem vegetal

\begin{tabular}{|c|c|c|c|c|c|c|c|c|c|c|}
\hline \multirow{2}{*}{ Farinhas } & \multicolumn{10}{|c|}{ Percentual de farinha $(\%)$} \\
\hline & 2 & 4 & 6 & 8 & 10 & 12 & 14 & 16 & 18 & 20 \\
\hline Aveia A & \pm & \pm & + & + & + & + & + & + & + & + \\
\hline Aveia B & \pm & \pm & \pm & \pm & \pm & + & + & + & + & + \\
\hline Banana & - & \pm & \pm & \pm & \pm & \pm & + & + & + & + \\
\hline Feijão Branco & - & \pm & \pm & \pm & \pm & \pm & + & + & + & + \\
\hline Linhaça Dourada & - & - & - & - & \pm & \pm & \pm & \pm & + & + \\
\hline Linhaça Marrom & - & - & - & - & - & \pm & \pm & \pm & \pm & \pm \\
\hline Maracujá & - & - & - & - & - & - & \pm & \pm & \pm & \pm \\
\hline Soja & - & - & - & - & - & - & - & - & - & - \\
\hline Trigo Integral & - & \pm & \pm & \pm & \pm & \pm & \pm & \pm & \pm & \pm \\
\hline Trigo Branca & \pm & \pm & \pm & \pm & \pm & + & + & + & + & + \\
\hline Uva & - & - & - & - & - & - & - & - & - & - \\
\hline
\end{tabular}

Testes realizados em triplicata: Ausência de gelificação (-); Gel frágil ( \pm ); Gel resistente (+). 
Como pode ser demonstrado neste trabalho, o estudo das propriedades funcionais é de extrema importância, pois a partir dele é possível recomendar a aplicação de um determinado ingrediente na produção alimentícia. Além disso, foi possível verificar que até mesmo entre as marcas encontradas no mercado existe diferença entre estas propriedades.

\section{Conclusões}

De acordo com os resultados obtidos e dentro das condições adotadas no presente estudo, conclui-se que: a farinha de maracujá apresentou boas propriedades de absorção de água e óleo e solubilidade em água. Todas as farinhas estudadas apresentaram valores satisfatórios de absorção de óleo, indicando que há possibilidade de utilização desses produtos no preparo de produtos cárneos ou em produtos emulsionados como massas de bolos, maionese, molhos para saladas, dentre outros.

As farinhas de aveia, banana, feijão branco, linhaça dourada e marrom, maracujá, soja e trigo integral demonstraram atividade emulsificante interessante para a indústria de alimentos, indicando possibilidades de utilização destas farinhas na formulação de produtos cárneos. As farinhas de aveia A e B e trigo branca, apresentaram boa capacidade de formação de gel sob baixas concentrações demonstrando que existe possibilidade de uso destas farinhas na formulação de mingaus, cremes e molhos.

As farinhas vegetais comerciais estudadas apresentam características que permitem seu uso como ingredientes com propriedades funcionais tecnológicas para diversas aplicações de interesse para a indústria de alimentos.

\section{Referências Bibliográficas}

ADEBOWALE, K. O.; LAWAL, O. S. Foaming, gelation and electrophoretic characteristics of mucuna bean (Mucuna pruriens) protein concentrates. Food Chemistry, Boston, v. 83, p. 237-246, 2003.

BATISTA, K. A.; PRUDÊNCIO, S. H.; FERNANDES, K. F. Changes in the biochemical and functional properties of the extruded hard-to-cook cowpea (Vigna unguiculata L. Walp). International Journal of Food Science \& Technology, Oxford, v. 45, p. 794-799, 2010.

BRASIL. Resolução - RDC no 263 de 22 de setembro de 2005a. Regulamento Técnico para produtos de cereais, amidos, farinhas e farelos. Diário Oficial da República Federativa do Brasil, Brasília, DF, 23 set. 2005, Seção1, p. $368-9$.

CASTILHO, F.; FONTANARI, G. G.; BATISTUTI, J. P. Avaliação de algumas propriedades funcionais das farinhas de tremoço doce (Lupinus albus) e feijão guandu (Cajanus cajan (L.) Millsp) e sua utilização na produção de fiambre. Ciência e Tecnologia de Alimentos, Campinas-SP, v. 30, n. 1, p. 6875, 2010.

CLERICI, M. T. P. S.; EL-DASH, A. A. Características tecnológicas de farinhas de arroz pré- gelatinizadas obtidas por extrusão termoplástica. Ciência e Agrotecnologia, Lavras-MG, v. 32, n. 5, p. 1543-1550, 2008.

COFFMANN, C. N.; GARCIA, V. V. Functional properties and amino acid content of a protein isolate from mung bean flour. International Journal of Food Science and Technology, Oxford, v. 12, n. 5, p. 473, 1977.

DENCH, J. E.; RIVAS, R. N.; CAYGILL, J. C. Selected functional properties of sesame (Sesamun indicum L.) flour and two protein isolates. Journal of the Science of Food and Agriculture, Washington, v. 32, n. 6, p. 557-564, 1981.

FENNEMA, O. R.; DAMODARAN, S.; PARKIN, K. L. Química de Alimentos de Fennema. 4. ed. Porto Alegre-RS: Editora Artmed, 2010. 900 p.

FIORDA, F. A.; SOARES JÚNIOR, M. S.; SILVA, F. A.; SOUTO, L. R. F.; GROSSMANN, M. V. E. Farinha de bagaço de mandioca: aproveitamento de subproduto e comparação com fécula de mandioca. Pesquisa Agropecuária Tropical, Goiânia-GO, v. 43, n. 4, p. 408-416, 2013.

GOMES, G. M. S.; REIS, R. C.; SILVA, C. A. D. T. S. Obtenção de farinha de feijão caupi (Vigna unguiculata L. Walp). Revista Brasileira de Produtos Agroindustriais, Campina Grande-PB, v. 14, n. 1, p. 31-36, 2012.

GUIMARÃES, R. C. A.; FAVORO, S. P.; VIANA, A. C. A.; BRAGA NETO, J. A.; NEVES, A V.; HONER, M. R. Study of the proteins in the defatted flour and protein concentrate of baru nuts (Dipteryx alata Vog.). Ciência e Tecnologia de Alimentos, Campinas-SP, v. 32, n. 3, p. 464-470, 2012.

KHATTAB, R. Y.; ARNTFIELD, S. D. Functional properties of raw and processed canola meal. LWT-Food Science and Technology, Oxford, v. 42, n. 6, p. 1119-1124, 2009.

LEONEL, M.; FREITAS, T. S.; MISCHAN, M. M. Physical characteristics of extruded cassava starch. Scientia Agricola, Piracicaba-SP, v. 66, n. 4, p. 486-493, 2009.

MIZUBUTI, I. Y.; BINDO JUNIOR, O.; SOUZA, L, W. O., SILVA, R. S. S. F.; IDA, EI. Propriedades funcionais da farinha e concentrado protéico de feijão guandu (Cajanus cajan (I.) Millsp). Archivos Latinoamericanos de Nutrición, Caracas, v. 50, n. 3, p. 274-280, 2000.

OKEZIE, B. O.; BELLO, A. B. Physicochemical and functional properties of winged bean flour and isolate compared with soy isolate. Journal of Food Science, Chicago, v. 53, n. 2, p. 450-454, 1988.

ORO, T.; LIMBERGER, V. M.; MIRANDA, M. Z.; RICHARDS, N. S. P. S.; GUTKOSKIL, L. C.; FRANCISCO, A. Propriedades de pasta de mesclas de farinha integral com farinha refinada usadas na produção de pães. Ciência Rural, Santa Maria-RS, v.43, n. 4, p. 754-760, 2013.

PORTE, A.; SILVA, E. F.; ALMEIDA, V. D. S.; SILVA, T. X.; PORTE, L. H. M. Propriedades funcionais tecnológicas das farinhas de sementes de mamão (Carica papaya) e de abóbora (Cucurbita sp). Revista Brasileira de Produtos 
Agroindustriais, Campina Grande-PB, v. 13, n. 1, p. 91-96, 2011.

RODRÍGUEZ-AMBRIZ, S. L.; MARTÍNEZ-HERNÁNDEZ, G.; GONZÁLEZ, J. E. C.; TRUJILLO, J.P.P. Composition and functional properties of Lupinus campestris protein isolates. Plants Foods for Human Nutrition, v. 60, p. 99107, 2005.

SEBIO, L.; CHANG, Y. K. Effects of selected process parameters in extrusion of yam flour (Dioscorea rotundata) on physicochemical properties of the extrudates. Nahrung, Alemanha, v. 44, n. 2, p. 96-101, 2000.

SEIBEL, N.F.; BELÉIA, A.P. Características químicas e funcionalidade tecnológica de ingredientes de soja [Glycine $\max ($ L.) Merrill]: carboidratos e proteínas. Brazilian Journal of Food Technology. Campinas-SP, v.12, n.2, p.113-122, 2009.

SIDDIQ, M., RAVI, R., HARTE, J. B.; DOLAN, K. D. Physical and functional characteristics of selected dry bean (Phaseolus vulgaris L.) flours. LWT - Food Science and Technology, Oxford, v. 43, n. 2, p. 232-237, 2010.

SILVA-SÁNCHEZ， C.; GONZÁLEZ-CASTANHEDA， J.; LÉON-RODRÍGUEZ, A.; BARBA DE LA ROSA, A. P. Functional and rheological properties of amaranth albumins extracted from two mexixan varieties. Plant Foods for human nutrition, Heidelberg, v. 59, n. 4, p. 169-174, 2004.

SILVEIRA, M. L. R.; SANTOS, O. S.; PENNA, N. G.; SAUTTER, C. K.; ROSA, C. S.; BERTAGNOLLI, S. M. M. Aproveitamento tecnológico das sementes de goiaba (Psidium guajava L.) como farinha na elaboração de biscoitos. Boletim CEPPA, Curitiba-PR, v. 34, n. 1, p.1-21, 2016.
SOUZA, M.W.S.; FERREIRA, T.B.O.; VIEIRA, I.F.R. Centesimal composition and functional technological properties of passion fruit rind flour. Alimentos e Nutrição, Araraquara-SP, v. 19, n. 1, p. 33-36, 2008.

TAVARES, J. A. S.; SOARES JÚNIOR, M. S.; BECKER, F. S.; COSTA, E. E. Mudanças funcionais de farinha de arroz torrada com micro-ondas em função do teor de umidade e do tempo de processamento. Revista Ciência Rural, Santa Maria-RS, v. 42, n. 6, p. 1102-1109, 2012.

WANG, S. H.; MAIA, L. H.; CABRAL, L.C.; GERMANI, R.; BORGES, J. T. S. Influência da proporção arroz:soja sobre a solubilidade $\mathrm{e}$ as propriedades espumantes dos mingaus desidratados. Ciência e Tecnologia de Alimentos, CampinasSP, v. 20, n.1, p.83-89, 2000.

YASUMATSU, K.; SAWADA, K.; Moritaka, S.; MISAKI, M.; TODA, J.; WADA, T.; ISHII, K. Whipping and emulsifing properties of soy bean products. Journal of Agriculture and Biology Chemistry, Nagoya, v. 36, n. 5, p. 719-727, 1972.

ZAMBRANO, M. L.; MELÉNDEZ, R.; GALLARDO, Y. Propriedades funcionales y metodología para su evaluación en fibra dietética. In: LAJOLO, F.; SAURA-CALIXTO, E.; WITTING, W. M Fibra dietética en Iberoamérica: Tecnología y Salud. Obtención, caracterización, efecto fisiológico y aplicación en alimentos. São Paulo-SP: Livraria Ltda, 2001. p. 195-209. 